động giám sát phản ứng có hại của thuốc (ADR) tai các cơ sở khám, chữa bệnh.

2. Bộ Y tế (2015), Hướng dẫn quốc gia về Cảnh giảc Dược, Nhà xuất bản Thanh Niên .

3. WHO (2003), WHO Toxicity Grading scale for determining the severity of adverse events

4. Trung tâm DI \& ADR Quốc gia TỔNG KẾT CÔNG TÁC BÁO CÁO ADR NÁM 2019

5. Trân Thị Lan Anh, Trân Ngân Hà và CS (2015) "Khảo sát kiến thức và thực hành của cán bô y tế vế báo cáo phản ứng có hại của thuốc tại 3 bệnh viện tuyến tỉnh", Tap chí Dước hoc, 55 (6) ), tr. 6-11

6. Nguyê̂n Thị Thanh Hướng, Nguyễn Phương
Chi và CS (2016) "Thực trang kiến thức, thái độ và thực hành của cán bố y tế vể báo cáo phản ứng có hai của thuốc tại mười bệnh viện đa khoa tuyến tỉnh", Tạp chí Dược học số 7, tr.2-5.

7. Asmatanzeem Bepari, et al (2020) "The comparative evaluation of knowledge, attitude, and practice of different health-care professionals about the pharmacovigilance system of India", Saudi Pharmaceutical Journal.

8. Santosh KC et al, "Attitudes among healthcare professionals to the reporting of adverse drug reactions in Nepal", BMC Pharmacology and Toxicology, 5, 2013, pages 14.

\title{
NGHIÊN CỨU NỒNG Độ DOPAMIN CÙNG CÁC CHẤT CHUYỂN HÓA CỦA DOPAMIN TRONG DICH NÃO TỦY VÀ MỐI LIÊN QUAN VỚI MỘT SỐ BIỂU HIỆN LÂM SÀNG Ở BÊ̂NH NHÂN MẮC BỆNH PARKINSON
}

\author{
Nguyễn Đức Thuận ${ }^{1}$, Nhữ Đình Sơn' ${ }^{1}$, Nguyễn Hũu Quang ${ }^{2}$, \\ Lê Văn Quân ${ }^{1}$, Hoàng Thị Dung ${ }^{1}$, Trịnh Văn Quỳnh ${ }^{1}$
}

\section{TÓM TẮT}

Muc tiêu: Nghiên cứu nồng độ dopamin cùng các chất chuyển hóa của dopamin (DOPAC) trong dịch não tủy và mối liên quan với một số biểu hiện lâm sàng ở bệnh nhân mắc bệnh Parkinson. Đối tượng và phương pháp: Tiến cứu, mô tả cắt ngang có so sánh với nhóm chứng. Phương pháp chọn mẫu: Chọn mẫu thuận tiện. Xét nghiệm định lượng nồng độ dopamin, DOPẢC dịch não tủy cho cả nhóm bệnh và nhóm chứng. Kết quả: Nồng đô dopamin dich não tủy ở nhóm chứng giá trị trung bình là $31,85 \pm 12,56 \mathrm{pg} / \mathrm{ml}$ trong khi ơ nhóm bệnh nhân Parkinson là $20,10 \pm 3,52 \mathrm{pg} / \mathrm{ml}$. Nồng độ DOPAC dịch não tủy ở nhóm chứng giá tri trung bình là $7,03 \pm 4,14 \mathrm{ng} / \mathrm{ml}$ trong khi ơ bênh nhóm bệnh nhân Parkinson là 3,75 $\pm 3,00 \mathrm{pg} / \mathrm{ml}$. Nồng độ dopamin, DOPAC dịch não tủy giảm dần từ giai đoạn bênh 1 đến giai đoạn 4,5. Sự khác biêt là có ý nghĩa thống kê $(p<0,001)$. Nồng độ dopamin, DOPAC dich não tủy giảm dần từ mức đồ bênh nhe đến mức độ nặng và rất nặng. Sự khác biệt là có ý nghĩa thống kế $(p<0,001)$. Nồng đợ dopamin, DOPAC dịch não tủy giảm dần từ không bị trầm cảm đến trầm cảm mức độ nhe, vừa và nặng. Sự khác biệt là có ý nghĩa thống kê $(p<0,05)$. Có sự tương quan nghịch có nghĩa thống kê giữa nồng độ dopamin dịch não tủy với thời gian mắc bệnh $(R=-0,764, p<0,001)$. Có sự tương quan nghich có nghĩa thống kê giữa nồng độ DOPAC dịch não tủy với thời gian mắc bệnh $(R=$ $0,690, p<0,001)$. Kết luận: Nghiên cứu chúng tôi cho thấy có sự giảm đáng kể nồng độ dopamin, DOPAC dịch não tủy ở bệnh nhân Parkinson so với

${ }^{1}$ Bệnh viện Quân y 103

${ }^{2}$ Trường đại hoc Buôn Ma Thuôt

Chịu trách nhiệm chính: Nguyển Đức Thuận

Email: nguyenducthuan@vmmu.edu.vn

Ngày nhận bài: 9.3.2021

Ngày phản biên khoa họ: 27.4.2021

Ngày duyệt bài: 10.5.2021 nhóm chứng, mức độ bệnh càng nặng, giai đoạn bệnh càng tăng thì nồng độ dopamin, DOPAC dịch não tủy càng giảm. Có Có sự tương quan nghịch có nghĩa thống kê giữa nồng độ dopamine, DOPAC dịch não tủy với thời gian mắc bênh.

Tư khóa: Bênh Parkinson; Nồng độ dopamine dịch não tủy; Nồng độ DOPAC dịch não tủy.

\section{SUMMARY}

RESEARCH OF THE CONCENTRATION OF DOPAMINE AND ITS METABOLITES IN THE CEREBROSPINAL FLUID AND ITS RELATIONSHIP WITH SOME CLINICAL MANIFESTATIONS IN PATIENTS WITH PARKINSON'S DISEASE

Objectives: To study the concentration of dopamine and its metabolites (DOPAC) in the cerebrospinal fluid (CSF) and its relationship with some clinical manifestations in patients with Parkinson's disease. Subjects and methods: Prospective, cross-sectional description with comparison with control group. Sampling method: Convenience sampling. Quantitative testing of dopamine and DOPAC levels of cerebrospinal fluid for both disease and control groups. Results: The mean concentration of dopamine in the control group was $31.85 \pm 12.56 \mathrm{pg} / \mathrm{ml}$ while in the Parkinson's group it was $20.10 \pm 3.52 \mathrm{pg} / \mathrm{ml}$. The mean DOPAC concentration of CSF in the control group was $7.03 \pm$ $4.14 \mathrm{ng} / \mathrm{ml}$ while in Parkinson's patients it was $3.75 \pm$ $3.00 \mathrm{pg} / \mathrm{ml}$. The concentration of dopamine, DOPAC of cerebrospinal fluid gradually decreased from stage 1 to stage 4.5. The difference is statistically significant $(p<0.001)$. The concentration of dopamine and DOPAC in the cerebrospinal fluid gradually decreased from mild disease to severe and very severe disease. The difference is statistically significant $(p<0.001)$. Dopamine levels, CSF DOPAC gradually decreased from no depression to mild, moderate and severe 
depression. The difference is statistically significant $(p<0.05)$. There was a statistically significant negative correlation between the concentration of dopamine in the cerebrospinal fluid and the duration of the disease $(R=-0.764, p<0.001)$. There was a statistically significant negative correlation between the CSF DOPAC concentration and the duration of the disease $(R=-0.690, p<0.001)$. Conclusion: Our study showed that there was a significant decrease in the concentration of dopamine, CSF DOPAC in Parkinson's patients compared with the control group, the more severe the disease, the more advanced the disease stage, the concentration of dopamine, DOPAC in cerebrospinal fluid. marrow decreases. There is a statistically significant negative correlation between the concentration of dopamine, DOPAC of cerebrospinal fluid and the duration of the disease.

Keywords: Parkinson's disease; CSF dopamine concentration; CSF DOPAC concentration.

\section{I. ĐẶT VẤN ĐỀ}

Bệnh Parkinson là bệnh lý thoái hóa thần kinh tiến triển thường gặp trên lâm sàng, đặc biệt là ở những người lớn tuổi [1]. Bệnh gây ảnh hưởng đến chức năng vận động, gây suy giảm chức năng lao động và sinh hoạt hàng ngày. Từ đó, làm giảm chất lượng sổng trên bệnh nhân Parkinson. Vì vậy, việc chẩn đoán và điều trị sớm là hết sức cần thiết.

Về mặt cơ chế bệnh sinh, các nghiên cứu trước đây cho rằng bệnh có liên quan đến tổn thương các tế bào thần kinh hê dopamin ở chất đen trên não bộ [2]. Tuy nhiên, các nghiên cứu cũng chỉ ra rằng các biểu hiện lâm sàng của bênh Parkinson chỉ được biểu hiện khi chất đen tổn thưởng khoảng $70-80 \%$ tế bào thần kinh hệ Dopamin [3]. Do đó, xác định sớm các tổn thương về các tế bào thần kinh hệ Dopamin vùng chất trước khi biểu hiện bệnh có ý nghĩa quan trọng trong chiến lược phòng ngừa và điều trị bệnh. 3,4-Dihydrophenylacetic acid (DOPAC) là chất chuyển hóa quan trọng của dopamin nên sự thay đổi nồng độ của DOPAC trong dịch não tủy là phản ảnh sự thay đổi nông độ của dopamin trong cơ thể, đăc biệt là ở hệ thần kinh trung ương. Một số nghiển cứu cho rẳng sự thay đổi nồng độ Dopamin, DOPAC dịch não tủy có thể là những chỉ dấu quan trọng liên quan đến tổn thương hệ thần kinh Dopamin nói trên $[6],[7],[8],[9]$. Trên cơ sở này, chúng tôi tiến hành nghiên cứu này nhằm mục tiêu: Nghiên cứu nồng độ dopamin cùng các chất chuyển hóa của dopamin (DOPAC) trong dịch não tủy và mối liên quan với một số biểu hiện lâm sàng ở bệnh nhân mắc bệnh Parkinson.

II. ĐỐI TƯợNG VÀ PHƯƠ'NG PHÁP NGHIÊN CỨU

2.1. Đối tượng nghiên cứu. 61 bệnh nhân nhóm bệnh được chẩn đoán bệnh Parkinson theo tiêu chuẩn của Hội Ngân hàng Não và Parkinson Vương quốc Anh đang điều trị nội trú tại Khoa Thần kinh, Bệnh viện Quân y 103 từ tháng 9/2018 đến tháng 2/2021.

40 bệnh nhân nhóm chứng có tuổi, giới, trình độ học vấn tương đương nhóm nghiên cứu. 40 người này có chỉ định chọc ống sống thắt lưng làm xét nghiệm dịch não tủy phục vụ các chẩn đoán các bệnh lý thần kinh như: viêm màng não, viêm não, viêm tủy, viêm não - tủy, viêm đa rễ thần kinh, xơ cứng rải rác, hội chứng ép tủy,... Sau khi kết quả xét nghiệm sinh hóa và tế bào bình thường; chúng tôi sẽ được lựa chọn làm xét nghiệm nhóm chứng.

Ngoài ra, không chọn bệnh nhân hoặc nhóm chứng trong các trường hợp: Bệnh nhân mắc các bệnh lý nội tiết ảnh hưởng lượng dopamin như: cường giáp, suy giáp, cường tuyến thượng thận, suy tuyến thượng thận, bệnh nhân mắc các bệnh lý cấp tính như: bệnh lý tim mạch, bệnh lý tâm thần như: tâm thần phân liệt, rối loạn cảm xúc lưỡng cực. Tiền sử nghiện ma túy và hoặc nghiện rượu. Bệnh nhân mù chữ hoặc rối loạn chức năng ngôn ngữ như đọc, nghe.

\subsection{Phương pháp nghiên cứu}

Thiết kế nghiên cứu: Tiến cứu, mô tả cắt ngang có so sánh với nhóm chứng.

Phương pháp chọn mẫu: Chọn mẫu thuận tiên.

Quy trình tiến hành: Bệnh nhân được chẩn đoán bệnh Parkinson, đồng ý tham gia nghiên cứu sẽ được phỏng vấn theo bệnh án nghiên cứu có săn, phân tích các các triệu chứng lâm sàng từng bệnh nhân, và đánh giá các thang điểm lâm sàng; lấy dịch não tủy xét nghiệm nồng độ Dopamin.

Thang điểm đánh giá lâm sàng:

+ Đánh giá mức độ rối loạn vận động theo thang điểm thống nhất đánh giá bệnh Parkinson phần III (UPDRS: Unified Parkinson's Disease Rating Scale).

+ Đánh giá giai đoạn bệnh theo Hoehn và Yahr gồm 5 giai đoạn, từ I đển V.

+ Chẩn đoán trầm cảm theo tiêu chuẩn ICD10 và Đánh giá mức độ trầm cảm theo thang điểm BECK

+ Chọc ống sống thắt lưng và xét nghiệm Dopamin, DOPAC dịch não tủy: Tiến hành choc ống sống thắt lưng theo đúng theo hướng dẫn quy trình kỹ thuật nội khoa chuyên ngành Thần kinh của Bộ Y Tế; lấy $2 \mathrm{ml}$ dịch não tủy, bảo quản ở nhiệt độ âm $83^{\circ} \mathrm{C}$; sau đó tiến hành xét nghiệm nồng độ dopamin bằng phương pháp sắc ký lỏng siêu hiệu năng 2 lần khối phổ tại Viện 
nghiên cứu Y Dược học Quân sự.

2.3. Xử lý số liệu: Các số liệu thu thập được xử lý theo thuật toán thống kê y học, sử dụng phần mềm SPSS 20. Giá trị $\mathrm{p}<0,05$ được coi là có ý nghĩa thống kê.

2.4. Đạo đức trong nghiên cứu: Bệnh nhân được giải thích đầy đủ, tự nguyện tham gia nghiên cứu và đồng ý lây dịch não tủy làm xét nghiệm.

\section{KẾT QUẢ NGHIÊN CỨU VÀ BÀN LUẬN}

Bảng 1. Nồng độ Dopamin, DOPAC dịch não tủy nhóm bệnh và nhóm chứng

\begin{tabular}{|c|c|c|c|}
\hline Nồng độ & $\begin{array}{c}\text { Nhóm beênh } \\
(\mathbf{n = 6 1})\end{array}$ & $\begin{array}{c}\text { Nhóm chứng } \\
(\mathbf{n = 4 0 )}\end{array}$ & $\mathbf{p}$ \\
\hline $\begin{array}{c}\text { Dopamin } \\
\text { (pg/ml) }\end{array}$ & $20,10 \pm 3,52$ & $31,85 \pm 12,56$ & $\begin{array}{c}\mathrm{P} \\
<0,001\end{array}$ \\
\hline $\begin{array}{c}\text { DOPAC } \\
\text { (ng/ml) }\end{array}$ & $3,75 \pm 3,00$ & $7,03 \pm 4,14$ & $\begin{array}{c}\mathrm{P} \\
<0,001\end{array}$ \\
\hline
\end{tabular}

Nồng độ dopamin dịch não tủy ở nhóm chứng giá trị trung bình là $31,85 \pm 12,56 \mathrm{pg} / \mathrm{ml}$ trong khi ở bệnh dao là 20,10 $\pm 3,52 \mathrm{pg} / \mathrm{ml}$. Nồng độ DOPAC dịch não tủy ở nhóm chứng giá trị trung bình là $7,03 \pm 4,14 \mathrm{ng} / \mathrm{ml}$ trong khi ở bệnh dao là $3,75 \pm 3,00 \mathrm{npg} / \mathrm{ml}$. Thống kê cho thấy nồng độ dopamin, DOPAC dịch não tủy ở nhóm bệnh nhân Parkinson thấp hơn có ý nghĩa thống kê so với ở nhóm chứng $(p<0,001)$.

Bảng 2. Môi liên quan giữa dopamin với giai đoạn bệnh

\begin{tabular}{|c|c|c|}
\hline $\begin{array}{c}\text { Giai đoạn } \\
\text { bệnh }\end{array}$ & $\begin{array}{c}\text { Dopamin } \\
(\mathbf{p g} / \mathbf{m l}) \\
(\mathrm{n}=61)\end{array}$ & $\begin{array}{c}\text { DOPAC } \\
\mathbf{( n g / m l}) \\
(\mathrm{n}=61)\end{array}$ \\
\hline Giai đoạn 1(1) & $23,53 \pm 1,59$ & $7,23 \pm 3,17$ \\
\hline Giai đoạn 2(2) & $20,74 \pm 2,03$ & $3,32 \pm 1,65$ \\
\hline Giai đoạn 3(3) & $18,22 \pm 2,11$ & $1,74 \pm 0,48$ \\
\hline $\begin{array}{c}\text { Giai đoạn 4 } \\
\text { và 5 (4) }\end{array}$ & $13,38 \pm 1,46$ & $1,13 \pm 0,35$ \\
\hline $\mathrm{p}$ & $\mathrm{P} 1-2,3,4<0,001$ & $\mathrm{P} 1-2,3,4<0,001$ \\
\hline
\end{tabular}

Nồng độ dopamin, DOPAC dịch não tủy giảm dần từ giai đoạn bệnh 1 đến giai đoạn 4,5. Sự khác biệt là có ý nghĩa thống kề $(p<0,001)$. Điều này gợi ý rằng giai đoạn bệnh càng tăng thì nồng độ dopamin, DOPAC dịch não tủy càng giảm.

Bảng 3. Môi liên quan giữa dopamin với mức độ bệnh

\begin{tabular}{|c|c|c|}
\hline $\begin{array}{c}\text { Mức độ } \\
\text { bệnh }\end{array}$ & $\begin{array}{c}\text { Dopamin } \\
(\mathbf{p g} / \mathbf{m l})(\mathrm{n}=61)\end{array}$ & $\begin{array}{c}\text { DOPAC(ng/ ml) } \\
(\mathrm{n}=61)\end{array}$ \\
\hline Nhẹ (1) & $23,02 \pm 1,50$ & $6,27 \pm 2,92$ \\
\hline Vừa (2) & $20,20 \pm 1,03$ & $2,19 \pm 0,55$ \\
\hline $\begin{array}{c}\text { Nặng và rất } \\
\text { nặng (3) }\end{array}$ & $15,62 \pm 2,15$ & $1,36 \pm 0,28$ \\
\hline $\mathrm{P}$ & $\mathrm{P} \mathrm{1-2,3<0,001}$ & $\mathrm{P} 1-2,3<0,001$ \\
\hline
\end{tabular}

Nồng độ dopamin, DOPAC dịch não tủy giảm dần từ mức đô bênh nhe đến mức độ năng và rất nặng. Sự khác biệt là có ý nghĩa thống kê $(p<0,001)$. Điều này gợi ý rằng mức độ bệnh càng nặng thì nồng độ dopamin, DOPAC dịch não tủy càng giảm.

\section{Bảng 4. Mối liên quan giữa dopamin với} tràm cám

\begin{tabular}{|c|c|c|}
\hline $\begin{array}{c}\text { Mức độ trâm } \\
\text { cảm }\end{array}$ & $\begin{array}{c}\text { Dopamin } \\
(\mathbf{p g} / \mathbf{m l}) \\
(\mathrm{n}=61)\end{array}$ & $\begin{array}{c}\text { DOPAC } \\
\mathbf{( n g / m l )} \\
(\mathrm{n}=61)\end{array}$ \\
\hline $\begin{array}{c}\text { Không có trầm } \\
\text { cảm(1) }\end{array}$ & $22,29 \pm 2,40$ & $5,61 \pm 3,37$ \\
\hline Trầm cảm nhẹ(2) & $19,76 \pm 2,49$ & $2,57 \pm 1,68$ \\
\hline Trầm cảm vừa(3) & $17,29 \pm 3,73$ & $2,17 \pm 1,69$ \\
\hline Trầm cảm nặng(4) & $17,45 \pm 3,43$ & $1,91 \pm 1,02$ \\
\hline $\mathrm{p}$ & $\mathrm{P} 1-2,3,4<0,05$ & $\mathrm{P} 1-2,3,4<0,05$ \\
\hline
\end{tabular}

Nồng độ dopamin, DOPAC dịch não tủy giảm dần từ không bị trầm cảm đến trầm cảm mức độ nhe, vừa và nặng. Sự khác biệt là có ý nghĩa thống kê $(p<0,05)$. Điều này gợi ý rằng trầm cảm càng nặng thì nồng độ, DOPAC dịch não tủy càng giảm.

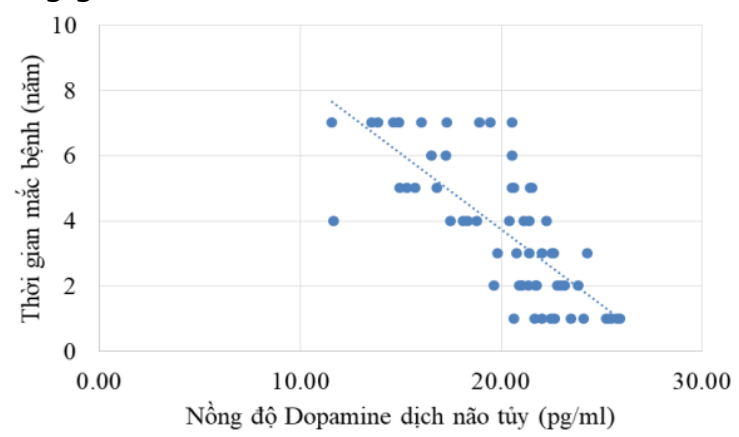

Biểu đồ 2. Liên quan nồng độ dopamin dịch não tủy với thời gian mắc bệnh

Sử dung phương pháp phân tích tương quan hồi qui tuyến tính cho thấy có sự tương quan nghịch có nghĩa thống kê giữa nồng độ dopamin dịch não tủy với thời gian mắc bệnh $(R=-0,764$, $\mathrm{p}<0,001)$. Kết quả này gợi ý rằng thời gian mắc bệnh càng lâu nồng độ dopamin dịch não tủy càng giảm.

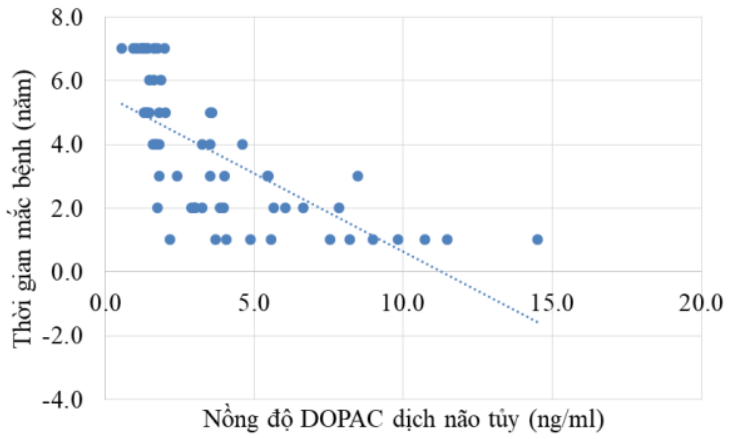

Biểu đồ 2. Liên quan nồng độ DOPAC dịch não tủy với thời gian mắc bệnh 
Sử dụng phương pháp phân tích tương quan hồi qui tuyến tính cho thấy có sự tương quan nghịch có nghĩa thống kê giữa nồng độ DOPAC dịch não tủy với thời gian mắc bệnh $(R=-0,690$, $\mathrm{p}<0,001)$. Kết quả này gợi ý rằng thời gian mắc bệnh càng lâu nồng độ DOPAC dịch não tủy càng giảm

Trong nghiên cứu này, chúng tôi tiến hành phân tích mối liên quan giữa sự thay đổi nồng độ dopamin, DOPAC dịch não tủy với một số đặc điểm lâm sàng. DOPAC là chất chuyển hóa quan trọng của dopamin nên sự thay đổi nồng độ của DOPAC trong dịch não tủy là phản ảnh sự thay đổi nồng độ của dopamin trong cơ thể, đặc biệt là ở hệ thần kinh trung ương.

Đầu tiên Nồng độ dopamin, DOPAC dịch não tủy giảm rõ rệt trên bệnh nhân Parkinson so với chứng không mắc bệnh. Điều này có thể giải thích bới cơ chế bệnh sinh của bệnh Parkinson có liên quan chặt chẽ đến hoạt động của tế bào thần kinh dopamin. Người ta đã chứng minh được rằng bệnh Parkinson có nguyên nhân là thoái hóa các tế bào dopamin trên hệ thần kinh trung ương, đặc biệt là vùng chất đen. Các biểu hiện lâm sàng của bệnh được biểu hiện khi tổn thưởng khoảng $31 \%$ tế bào thần kinh thuộc vùng này [4]. Sự thoái hóa các tế bào thần kinh dopamin là nguyên nhân quan trọng dẫn đến sự suy giảm nồng độ dopamin ở synap thần kinh của các tế bào dopamin. Khi nồng độ các dopamin ở synap thần kinh giảm sẽ giảm sự truyền tin từ các tế bào thần kinh dopamin ở vùng chất đen đến thể vân, là nguyên nhân dẫn đến rối loạn vận động và thăng bằng trên bệnh nhân Parkinson [5]. Kết quả của chúng tôi cũ̃ng phù hợp với kết quả của các nghiên cứu trước đây; Hoàng Thị Dung (2014)[6], Nguyễn Đức Thuận và cộng sự (2020)[7]. Ngoài ra, theo Eldrup và cộng sự (1995), trên bệnh nhân Parkinson, có sự giảm nồng độ DOPAC dịch não tủy trong khi nồng độ dopamin không thay đổi có ý nghĩa thống kê [8]. Gần đây Goldstein và cộng sự (2012) cũng xác nhận kết quả nghiên cứu này [9].

Thứ hai, chúng tôi phân tích là mức độ bệnh. Bênh Parkinson được chia thành 4 mức độ: mức độ nhẹ, mức độ vừa, mức độ nặng và mức độ rất lớn. Phân chia mức độ này dựa vào thang điểm thống nhất đánh giá bệnh Parkinson (UPDRS - phần III) [10]. Thang điểm này liên quan rất lớn đến rối loạn vận động và thăng bằng trên bênh nhân Parkinson. Những triêu chứng này được cho là liên quan chặt chẽ đến hoạt động của dopamin trên hệ thần kinh trung ương. Vì vậy, mức độ bệnh có thể phản ánh mức độ rối loạn hoạt động của hệ dopaminrgic. Do vậy, khi mức độ bệnh càng nặng thì nồng độ dopamin, DOPAC giảm càng lớn.

Thứ ba là giai đoạn bệnh. Bệnh Parkinson được chia thành 5 giai đoạn tiến triển của bệnh. Vì vậy giai đoạn 4 và giai đoạn 5 thể hiện bệnh sớm hay muộn. Và một điều hiển nhiên là giai đoạn càng muộn thì thời gian bị bệnh càng lâu. Do vậy, kết quả của chúng tôi đã cho thấy giai đoạn bệnh càng muộn thì nồng dopamin, DOAPC dịch não tủy giảm càng mạnh.

Cuối cùng, nghiên cứu của chúng tôi cho thấy thời gian bị bệnh tỷ lệ nghịch với nồng độ dopamin, DOPAC dịch não tủy trên bệnh nhân Parkinson. Điều này nghĩa là thời gian bị bệnh càng lâu thì nồng độ dopamin, DOPAC dịch não tủy càng giảm. Kết quả này hoàn toàn phù hợp với cơ chế bệnh sinh của bệnh Parkinson [4], [5]. Bệnh Parkinson là bệnh thoái hóa tiến triển mạn tính các tế bào thần kinh dopamin. Vì vậy, thời gian bị bệnh càng lâu thì mức độ thoái hóa các tế bào thẩn kinh dopamin trên hệ thần kinh trung ương càng mạnh, kết quả làm giảm càng nhiều nồng độ dopamin dịch não tủy. DOPAC là chất chuyển hóa quan trọng của dopamin nên sự thay đổi nồng độ của DOPAC trong dịch não tủy là phản ảnh sự thay đổi nồng độ của dopamin trong cơ thể.

\section{KẾT LUẬN}

Nồng độ dopamin, DOPAC dịch não tủy ở nhóm bệnh nhân Parkinson giảm có ý nghĩa thống kê so nhóm chứng.

Nồng độ dopamin, DOPAC dịch não tủy nhóm bệnh nhân Parkinson giảm dần có ý nghĩa thống kể theo mức độ nặng của bệnh và giai đoạn bệnh, mức độ trẩm cảm.

Nồng độ dopamin, DOPAC dịch não tủy bệnh nhân Parkinson có tương quan hồi qui tuyến tính cho thấy có sự tương quan nghịch có nghĩa thống kê với thời gian mắc bệnh.

\section{TÀI LIỆ THAM KHẢO}

1.Huquilin-Arista, Alvarez-Avellon F.T, Menendez-Gonzalez M. Prevalence of Depression and Anxiety in Parkinson Disease and Impact on Quality of Life: A Community-Based Study in Spain, J Geriatr Psychiatry Neurol. 2019. p.1-7.

2. Fahn S., Sulzer D. Neurodegeneration and neuroprotection in Parkinson disease. NeuroRx. 2004;1(1):139-154.

3. El-Agnaf O.M.A, Salem S.A, Paleologou K.E, et al. Detection of oligomeric forms of (-synuclein protein in human plasma as a potential biomarker for Parkinson's disease. FASEB J. 2006; 20: 419-425.

4. Fearnley J.M, Lees A.J. Ageing and Parkinson's 
disease: substantia nigra regional selectivity. Brain. 1991; 114:2283-2301.

5. Bisaglia M., Filograna R., Beltramini M., et al. Are dopamin derivatives implicated in the pathogenesis of Parkinson's disease? Ageing Research Reviews. 2014; 13:107-114.

6. Hoàng Thị Dung (2014), Nghiên cứu đặc điểm lâm sàng và định lượng nông độ Dopamin huyết tương ở bệnh nhân Parkinson, Luận văn thạc sỹ Y hoc, Hoc viên Quân Y, Hà Nôi.

7. Nguyến Đức Thuận, Lê Văn Quân, và Nhữ Đinh Sơn (2020). Thay đổi nông đố Dopamin huyết tương trên bệnh nhân Parkinson. Tạp chí Y dược học quân sự, 2, 116-121.
8. Eldrup E., Mogensen P., Jacobsen J., et al. CSF and Plasma Concentrations of Free Norepinephrine, Dopamin, 3,4-dihydroxyphenylacetic Acid (DOPAC), 3,4-dihydroxyphenylalanine (DOPA), and Epinephrine in Parkinson's Disease. Acta Neurol Scand. 1995; 92(2):116-21.

9. Goldstein S., Holmes C., Sharabi $Y$. Cerebrospinal fluid biomarkers of central catecholamine deficiency in Parkinson's disease and other synucleinopathies. Brain, 2012; 135(6): 1900-1913.

10. Functional and Streotactic Neurology Staging of Parkinson's Disease. MGH Neurosugical Service 1999.

\section{KẾT QUẢ QUẢN LÝ ĐIỀU TRI LAO KHÁNG RIFAMPICIN TẠI THÁI NGUYÊN GIAI ĐOẠN 2016-2020 VÀ MỘT SỐ YẾU TỐ LIÊN QUAN}

\section{Đào Thị Hương ${ }^{1}$, Hoàng Hà², Trần Thế Hoàng²}

\section{TÓM TẮT}

Mục tiêu: Mô tả kết quả quản lý điều trị lao kháng Rifampicin tai Thái Nguyên giai đoan 20162020 và một số yếu tố liên quan. Phương pháp nghiên cứu: nghiên cứu mô tả cắt ngang trên 92 bệnh nhân lao kháng Rifampicin giai đoạn 2016-2020 tại Bệnh viện Lao và Bệnh phổi Thái Nguyên. Kết quả: Tuổi trung bình của bệnh nhân lao kháng Rifampicin là 40,9 12,3 , tỉ lệ nam $79,3 \%$. Tỉ lệ có tiền sử điêu trị lao $73,9 \%$, lao mói $26,1 \%$ và $H I V(+)$ $19,6 \%$. Tî lệ lao tại phối $97,8 \%$; thể $A F B(+) 72,8 \%$. Tì lệ tuân thủ xét nghiệm trong quá trình theo dõi điều trị $28,3 \%$. Tỉ lệ điều trị khỏi 3,5\%, hoàn thành điêu trị $75,5 \%$, tử vong $10,5 \%$, thất bại $2,3 \%$, bỏ trị $7,0 \%$, chuyên 1,2\%. Có mối liên quan giữa: tình trạng kinh tế hô gia đình nghèo, tiền sứ lao, mắc bênh kèm theo, $\mathrm{HIV}(+), \mathrm{AFB}(+)$, thời gian điều trị 20 tháng, bệnh nhân tai trai giam, không tuân thủ xét nghiêm và găp tác dụng không mong muốn với kết quả điều trị lao kháng Rifampicin khồng thành công $(p<0,05)$. Kết luận: Tỉ lệ điều trị lao kháng Rifampicin thành công tai Thái Nguyên tương đối cao, các yếu tố về đăc điểm bệnh và tiền sử bệnh có liên quan đến kết quả điêu tri không thành công.

Tư khóa: Quản lý điều trị; Lao kháng Rifampicin; Thái Nguyên.

\section{SUMMARY \\ RESULTS OF TREATMENT MANAGEMENT OF RIFAMPICIN-RESISTANT TUBERCULOSIS IN THAI NGUYEN PERIOD 2016-2020 AND SOME RELATED FACTORS}

\footnotetext{
${ }^{1}$ Bệnh viện Lao và Bệnh phổi Thái Nguyên

${ }^{2}$ Trường Đại hoc Y Dược Thái Nguyên

Chịu trách nhiệm chính: Đào Thị Hương

Email: daohuong1408@gmail.com

Ngày nhân bài: 5.3 .2021

Ngày phản biên khoa hoc: 28.4.2021

Ngày duyệt bài: 11.5.2021
}

Objectives: To describe the results of treatment management of rifampicin-resistant tuberculosis in Thai Nguyen period 2016-2020 and some related factors. Research Method: A cross-sectional descriptive study was conducted on 92 rifampicinresistant patients in the period 2016-2020 at Thai Nguyen Tuberculosis and Lung Disease Hospital. Results: The mean age of rifampicin-resistant patients was $40.9 \pm 12.3$, the male proportion was $79.3 \%$. The proportion of TB retreatment was $73.9 \%$, new cases $26.1 \%$ and $\mathrm{HIV}(+) 19.6 \%$. The proportion of lung TB was $97.8 \%$; $\mathrm{AFB}(+) 72.8 \%$. The proportion of testing adherence during treatment follow-up was $28.3 \%$. The proportion of cure $3.5 \%$, treatment completed $75.5 \%$, death $10.5 \%$, failure $2.3 \%$, dropout $7.0 \%$, transferred out $1.2 \%$. There were relationship between: poor household economic status, TB retreatment, comorbidities, $\operatorname{HIV}(+), \operatorname{AFB}(+), 20$ months treatment duration, patients in prison, non-testing adherence and had adverse drug reaction with unsuccessful treatment of rifampicin-resistant $(p<0.05)$. Conclusion: The proportion of RR-TB successful treatment in Thai Nguyen is relatively high, the retreatment and disease characteristics factors are related to unsuccessful treatment.

Keywords: Treatment management; Rifampicinresistance tuberculosis; Thai Nguyen.

\section{I. Đă̆T VẤN ĐỀ}

Lao kháng thuốc là một vấn đề sức khỏe lớn và đe dọa nghiêm trọng đến các nỗ lực kiểm soát và phòng ngừa bệnh lao trên toàn câu. Việt Nam là nước đứng thứ 11 trong 30 quốc gia có gánh nặng bệnh lao đa kháng thuốc cao nhất thế giới với 3266 bệnh nhân lao kháng thuốc thu nhận điều trị năm 2020 [1], [7]. Trong lao kháng thuốc, lao kháng Rifampicin (RR-TB) (thuốc thiết yếu điêuu trị lao) đang diễn biến phức tap [7]. Năm 2020, Việt Nam phát hiện 3503 bệnh nhân RR-TB trong tổng số 213.375 người được thực 